\title{
Maria Moisés e a novela épica camiliana
}

José Carlos Siqueira1

RESUMO: Neste artigo, propomos que Camilo Castelo Branco em sua "novela do Minho", Maria Moisés, mais do que articular estratégias românticas e realistas, se propôs com sucesso a uma mistura de gêneros e discursos, tendo como base a épica antiga. Com essa mescla, Camilo conseguia dar conta de representar os conflitos de seus tempos, mas marcava também uma posição mais construtiva em relação à escola realista, pondo a estrutura de mito a serviço de sua visão utópica.

ABSTRACT: In this article, we propose that Camilo Castelo Branco in his "novella of the Minho", Maria Moisés, much more than to articulate romantic and realistic strategies, he successfully proposed a mixture of genres and discourses based on the old epic. From that mixture, Camilo accounted for the conflicts of his time, and at the same time, he marked a more constructive position in relation to the realistic school, by putting the mythical structure at service of his utopian vision.

PALAVRAS-CHAVE: Camilo Castelo Branco, Maria Moisés, mistura de estilos, épica.

KEYWORDS: Camilo Castelo Branco, Maria Moisés, mixture of styles, epic.

\section{A diversidade discursiva da obra de Camilo Castelo Branco}

Num primeiro contato com a produção de Camilo Castelo Branco, o que mais nos chama a atenção é a extensão de sua obra e a variedade de gêneros pelos quais transitou: poesia, novela, teatro, crítica, etc. Já numa abordagem mais atenta, percebemos ainda que essa variedade está presente no interior de seus textos, nos quais ele mistura gêneros, estilos e, até, escolas estéticas diferentes, às vezes sendo julgado pela crítica tradicional como atingindo resultados duvidosos, mas sempre com a ressalva de que demonstra uma grande competência criativa: "Se analisarmos as partes heterogêneas e deficientemente cerzidas entre si,

\footnotetext{
${ }^{1}$ Mestre em Estudos Comparados de Literaturas de Língua Portuguesa, FFLCH-USP. Pesquisa: Segunda fase da obra de Eça de Queirós.
} 
cada uma delas constitui por si, uma pequena obra-prima”, declaram Saraiva e Lopes (s/d, p. 822) a respeito de A Brasileira de Prazins, uma obra que exemplifica muito bem a diversidade por nós apontada.

Sobre esse assunto, os críticos citados chamaram a atenção para a interessante mescla entre a estética romântica e a realista feita por Camilo principalmente a partir de As novelas do Minho. Dizem eles que, sem abandonar a estrutura da novela passional romântica, o escritor vai enxertando em suas histórias observações realistas, capazes de dar contundência ao texto e de levantar mordazes críticas sociais. A observação é apoiada no exemplo de Maria Moisés - objeto do presente trabalho - e em outras obras, nas quais "o que interessa é que nelas se engastam longas cenas de antologia realista” (ib., p. 820).

Apesar dessa qualidade, estudiosos como os mencionados Saraiva e Lopes, acompanhados por críticos consagrados como Jacinto do Prado Coelho, Alexandre Cabral, entre outros, não dedicam às Novelas do Minho o mesmo apreço que têm por Amor de Perdição e A queda de um anjo, textos que respectivamente representam o melhor das duas vertentes características da produção camiliana: o romance passional e a novela satírica de costumes. ${ }^{2}$ Segundo o pensamento dominante até pouco tempo na crítica portuguesa, "as Novelas do Minho acabam aí sendo obra de menor relevância típica, e de menor importância estética, pois não se operaria nelas a síntese das duas tendências básicas da ficção camiliana” (Franchetti, 2003, p. XI).

Felizmente, novas abordagens analíticas estão, por ora, pondo de lado o dualismo passional-satírico que a fortuna crítica de Camilo consagrou, para a partir de outras perspectivas teóricas e metodológicas reavaliar inclusive as "obras menores" do autor de Ceide. Para Paulo Franchetti,

a genialidade de Camilo está em utilizar criticamente as expectativas de leitura e as formas em que se cristalizam, sejam elas a novela sentimental, a novela picaresca, ou a narrativa

2 Conforme a excelente síntese que Paulo Franchetti faz da tradição crítica camiliana (2003, p. X e seguintes). 
naturalista. O que quer dizer que a matéria principal dos seus textos são as imagens da narrativa e da sua função na sociedade burguesa (Franchetti, 2003, p. xxxii).

Sendo que tais estratégias "geniais" podem ser principalmente observadas nos "prólogos, dedicatórias, notas de rodapé e digressões internas ao texto das novelas freqüentemente espezinham o gosto dominante, denunciam expectativas de leitura limitadas ou rebaixadas" (ib., p. xxxi). Ou seja, é no jogo entre aquilo que o leitor mediano espera do texto romanesco e a arguta compreensão que o escritor tem do seu fazer artístico que surge um tipo de enunciado que dá à obra camiliana uma qualidade e uma dimensão modernas (cf. ib., p. xxxii).

Por nossa vez, cremos importante que a crítica literária dê maior atenção para a diversidade existente internamente na novela camiliana, pois ela não é apenas uma marca pessoal, mas uma qualidade excepcional que, segundo nosso entender e no mesmo sentido apontado por Franchetti, antecipa as vanguardas modernistas. Escrever utilizando vários estilos e gêneros diferentes na mesma obra fez parte das estéticas de um James Joyce, de um Mário de Andrade ou de um Oswald.

É certo que o gênero base do escritor de Maria Moisés é a "novela passional”, mas, de forma sutil, personalíssima, ele vai rompendo com as limitações do gênero e, mais, vai superando as estéticas vigentes em seu tempo. Quando Lopes e Saraiva marcam como defeito o fato de que nenhuma das obras em que nosso autor mescla romantismo com realismo ser "perfeitamente homogênea, solidamente carpinteirada" (op. cit., p. 820), julgamos tratar-se de uma avaliação imprópria, pois lhe falta esta perspectiva: perceber aquela fusão como superação das condições estéticas do momento. Os dois críticos trabalham exclusivamente dentro dos limites do século XIX (romantismo versus realismo), ${ }^{3}$ talvez sem dar uma atenção especial às antecipações que Camilo estava processando. Sem dúvida, poderíamos concluir que esse

3 Ver a crítica semelhante de Franchetti em seu ensaio já citado (p. xxxii-xxxiiii). 
seria um dos bons motivos capazes de explicar a permanência da obra camiliana no presente.

\section{A diversidade discursiva em Maria Moisés}

Obra escrita no período final da vida do romancista, Maria Moisés é ainda um exemplo de outras misturas camilianas. Nela estão entrelaçados o romance passional, a observação realista, a sátira social, o conto moralista e o hagiográfico, o estudo genealógico e a digressão histórica. Mas Camilo, neste caso, nunca perde a mão e as inserções são feitas com tal cabimento e maestria, que uma outra qualidade se anuncia: a sensação de unidade. Existe o desenvolvimento de um todo harmônico, que sua leitura faz perceber com facilidade.

De acordo com a perspectiva desenvolvida, o que explicaria em Maria Moisés essa notável unidade que o mais distraído leitor consegue avaliar? Na história de Maria Moisés cada digressão, cada novo personagem, cada revelação, se encaixam de forma orgânica na narração. Nossa hipótese é que a estrutura profunda da novela está ancorada num grande gênero clássico que é apenas discretamente apontado no nome Moisés que dá título à obra: trata-se da narrativa épica, com sua ossatura rigidamente amarrada pelo tempo e que possibilitou ao nosso autor criar um enredo de grande organicidade.

Sem dúvida a referência ao mito mosaico ampara nossa hipótese - não há na Bíblia maior exemplo épico que esse, e note-se que não faltam epopéias no Livro Sagrado. Porém, se o autor do Pentateuco é o ponto de partida para a estruturação de Maria Moisés, não será ele o fio condutor dessa pequena narrativa épica. Camilo utilizou com perícia e criatividade um outro marco da literatura ocidental. Foi nas páginas da Odisséia que o escritor das Novelas do Minho achou o caminho para engrenar com engenhosidade sua história. A fim de tentar demonstrar tal hipótese, passemos a uma análise mais fina dessa novela. 


\section{A épica camiliana}

Nossa história começa in medias res, como manda o figurino épico: na primeira parte, Josefa da Laje, heroína trágica da novela, está em fuga, tentando transpor um vale sombrio e fechado para poder estar ao lado de António de Queirós, seu amado, e levar-lhe a filha que acabara de nascer. Os dois jovens não são casados e há um impedimento de ordem social entre eles, António é um fidalgo e seu pai não admite que ele se case com uma camponesa. Portanto, existem forças de vários níveis tentando impedir essa união, se acrescentarmos um padre que conhece o segredo e o denuncia ao pai do fidalgo; a mãe de Josefa, mulher rude e rigorosa que não aceitaria uma desonra por parte da filha. É necessário, por isso, a fuga de Josefa e sua união às escondidas com António.

A heroína sucumbe no meio da viagem, mas num último recurso ela solta a filha recém-nascida na águas do rio que atravessava, dentro de um cesto de vime. Eis a cena capital que dá nome à menina salva do rio e título ao livro. Mas, mais do que isso, é a chave para a leitura épica que propomos neste trabalho. O nascimento e o resgate das águas do rio conferem a Maria Moisés uma estatura épica, e a narração seguinte de sua vida pode, portanto, ser feita sob essa ótica.

Apesar disso, se a referência bíblica dá a chave para a épica, não é a história mosaica que estrutura a novela. Camilo não tem a intenção de contar a epopéia do salvador de um povo, mas de um herói que se desenvolve como indivíduo e propõe novas formas de sociabilidade, como é o caso da Odisséia. Se estivermos certos, Moisés ao mesmo tempo fornece o nexo épico da novela de Camilo, mas acaba funcionando como uma cortina de fumaça, ao encobrir o modelo estruturante, no caso, o retorno de Ulisses. Segundo nossa análise, o romancista português também exige um leitor atento, capaz de uma leitura crítica. ${ }^{4}$

\footnotetext{
4 Ver acima a citação de Paulo Franchetti, em que ele indica que Camilo ironizava em
} 
A divisão em duas partes dessa obra é mais uma chave para nossa hipótese. A Odisséia possui também duas grandes divisões reconhecidas pela crítica tradicional: a Odisséia, propriamente dita, que conta as viagens de Ulisses, e a Telemaquia, que narra a busca empreendida pelo filho de Ulisses, Telêmaco, para encontrar o pai. A Telemaquia foi um tema especialmente preferido pelo séc. XVIII Fénelon, seu maior promotor, utilizou-a de forma didática no romance As aventuras de Telêmaco. Homero, em seus cantos, faz Telêmaco crescer diante dos olhos do leitor, passando de um rapazola ingênuo a um homem capaz de administrar a casa de seu pai e ajudá-lo, em seu retorno, a liquidar os pretendentes de Penélope. Camilo vai se apropriar desses modelos de maneira original e livre, porém sem perder seu conteúdo simbólico e, principalmente, suas articulações narrativas.

Mas outros dados podem ser anuídos nessa primeira metade para manter-se a analogia sugerida com o clássico grego. António, o fidalgo enamorado de Josefa, está preso no Limoeiro e possui pretendentes com quem deve se casar, mas as quais ele repudia, como o fez Penélope. Ele precisa que Josefa escape da casa paterna, viaje até um lugar seguro, onde possam se casar e assim se desvencilhar de um casamento arranjado. Enfim, e apenas de passagem, é o núcleo modificado dos pretendentes de Penélope.

\section{A Telemaquia camiliana}

Morta Josefa, António então veste o figurino de Ulisses e parte para uma guerra no Brasil. Como no livro de Homero, no qual as narrativas de Odisseu e Telêmaco se intercalam, Camilo interrompe a história de António e inicia a narrativa da criança abandonada na correnteza do rio. É o início da Telemaquia camiliana. O bercinho de vime é resgatado por um pescador que o entrega aos seus patrões, uma casa fidalga. A família rica apadrinha a criança abandonada, uma

seus textos as expectativas rebaixadas do leitor médio. 
menina recém-nascida, a qual batizam com o nome de Maria Moisés, devido às circunstância similares a do patriarca hebreu. Maria cresce amparada por esses senhores e, quando jovem, herda uma modesta fortuna e a propriedade em que cresceu, próxima ao rio de seu resgate.

Sem pais, educada de forma religiosa, Maria Moisés quando adulta se propõe a uma missão heróica, criar um lar no qual crianças enjeitadas como ela pudessem ser abrigadas com carinho e conforto. Forma que ela encontrou para retribuir de algum jeito o bom destino que teve ao ser salva pelo pescador.

Temos aqui um paralelo sutil e simbólico com a história de Telêmaco. O herói grego sai pelo mundo em busca de informações de seu pai, tentando assim resgatar os elos de sua origem. Maria vai em busca de outras crianças, que, como ela, foram abandonadas pelos pais, numa nítida tentativa de unir os elos de sua existência, realizar em si os pais que não teve e fechar um círculo de abandonos e adoções. Não podemos esquecer que as interpretações sobre Telêmaco também apontam para a necessidade do jovem de tornar-se um homem e, assim, poder substituir seu pai no futuro.

De mesma forma como aparentemente Telêmaco fracassa em sua missão, Maria também não parece atingir seus objetivos. As dificuldades que vão surgindo na administração do pequeno orfanato vão inviabilizando o projeto e fazendo ruir seus sonhos. Mas é nessa condição que ele acaba se colocando pronta para reencontrar o pai do mesmo modo que Telêmaco, ao retornar amadurecido de sua viagem, está em condições de encontrar Odisseu e auxiliá-lo a recuperar o que é seu por direito.

A estudiosa portuguesa Maria Alzira Seixo, em um ensaio publicado em livro em 2004, também vê no tema do "regresso" uma das idéias estruturadoras da novela, não sendo por acaso que o ensaio e o livro que o contém recebem o título $O$ rio com regresso. No caso dessa autora, ela atribui ao rio Tâmega, que leva a vida de Josefa, o berço com a filha e as esperanças de uma vida feliz dos amantes, a função também 
de trazer de volta o pai exilado e as relações perdidas. Nas palavras de Seixo, o significado de rio seria

\begin{abstract}
uma espécie de fluxo impetuoso e erosivo, um movimento de perda, de algo que se escapa e se ignora, uma corrente avassaladora e inelutável, mas por outro lado beneplácita e epifânica (figurada nesse rio que acompanha a narrativa), que não é bem um correr "atrás de" (pois dá conta do nada que esse movimento evasivo encontra) mas talvez mais "a partir de", e tem portanto o selo do nascimento, da partida, da abalada, e que no caso do rio, simbolicamente sem regresso, vai aqui corresponder, ao invés, ao regresso de um humano que se configura a partir da evanescência das suas águas (da criança deitada a perder, do pai desaparecido, dos bens de fortuna que se gastam), no qual a partida é sempre uma determinação de encontro, mesmo se não lograda, e a abalada (ou o nascimento) sempre um estímulo para a vida e para a criação (p. 121-2 - itálicos da autora).
\end{abstract}

Não parece descabido aqui, fazer portanto um paralelo entre o Tâmega camiliano e o Mediterrâneo homérico, águas que levam e trazem os heróis épicos.

Seguindo tal indicação, vemos na segunda parte, António de Queirós, após 37 anos de auto-exílio, regressar a sua propriedade, próxima à vila onde Maria Moisés luta para manter o orfanato. Em cenas em que o rio Tâmega é cenário, mas também uma estratégia narrativa poderosa, o velho general fica sabendo por antigos amigos e conhecidos da existência da filha, que, até então, não tinha consciência de que nascera antes da morte de Josefa. Conhece as obras que a filha realizou em prol dos órfãos e as dificuldades pelas quais passa no momento.

Do mesmo modo como Ulisses entrou disfarçado de mendigo em Ítaca, e apenas se revelou ao filho após alguma peripécia; assim, António de Queirós foi conduzido à propriedade da filha, que estava à venda para pagar as dividas de seu assistencialismo, e, passando-se por um potencial comprador da quinta, fez várias solicitações à benfeitora dos pobres. Ao ver reunidas as treze crianças que ela abrigava e educava, António de forma poética se dá a conhecer: "Se eu morrer debaixo da luz dos teus olhos, Deus me chamará a si, não pelos meus 
merecimentos, mas pelas virtudes de minha filha. Pedirás então a Deus por teu pai, Maria?” (Castelo Branco, s/d, p. 84). Compare-se com a fala de Ulisses na mesma situação: "Nenhum dos deuses eu sou; por que a um deus imortal me comparas? Sou, sim teu pai, por quem hás suspirado, saudoso, já tanto e tantas dores sofrido, agüentando a violência de estranhos" (Odisséia, XVI, 187-9). É a mesma elocução poética e solene que dá o tom às duas falas.

Dissemos acima que Camilo, apesar de utilizar com liberdade a construção do poema homérico foi fiel ao seu espírito, aos símbolos que o aedo grego teceu em seus versos. Se Ulisses recupera sua família e seu trono, e Telêmaco encontra seu pai e comprova sua capacidade de sucedê-lo, o mesmo ocorre com os dois personagens camilianos: a semelhança entre Maria Moisés e sua mãe é espantosa: "Maria era alta, refeita, loira e bela como Josefa, (...) era o retrato de sua mãe" (Castelo Branco, ib., p. 80) - fato que apenas António poderia comprovar, somente ele no decurso de todos aqueles anos pôde guardar intacta na memória a imagem da amada. O militar recuperava, de certo modo, a esposa perdida juntamente com a única filha. Por seu lado, o esforço de Maria em buscar o sentido de sua existência na benemerência aos filhos enjeitados foi a razão que lhe deu visibilidade para ser encontrada pelo pai, e agora, também de certo modo, ela estava apta a substituir, em seu papel filial, sua mãe no coração do pai.

\section{A forma épica em Maria Moisés}

Mas não é apenas na estrutura da novela que estão os paralelos com a épica de Homero, a forma também o denuncia. Já foi apontado o início da narração in medias res, como instruía o bom Horácio. Outra fórmula está nas diversas vozes narrativas que habilmente se sucedem para a exposição das histórias: ao narrador onisciente substitui um padre bem articulado; um diálogo teatral nos dá outra fatia do enredo; o narrador muda a impostação de voz e apresenta uma aula de genealogia. São esses modos que lembram as estratégias homéricas, 
como por exemplo os cantos VIII e IX da Odisséia, nos quais o narrador alterna a exposição com dois aedos feácios, para depois Odisseu tomar a palavra e, ele próprio, contar suas aventuras.

Também as construções sentenciosas, presentes em quantidade e alta qualidade, relembram em Camilo o rapsodo cego. São fórmulas solenes e judiciosas, cujo encaixe na narrativa revela um elevado grau de adequação. Veja-se: "Uma cousa verdadeira, que os maus homens quase sempre têm, é a crítica mordaz dos costumes. Percebem e farejam os atos mais abscônditos da sociedade, como se a sociedade fosse obra deles" (ib., p. 23). Compare-se com: "Quem é grosseiro e com os outros somente asperezas pratica, imprecações só recolhe de todos os homens terrenos, enquanto vivo; depois que se fina, maldizem-no todos" (Odisséia, XIX, 329-31).

\section{A finalidade mito-poética de Maria Moisés}

No final da obra, fechando com uma rapidez até exagerada a cena de reconhecimento entre pai e filha, Camilo nos oferece uma explicação importante: ele não pode desenvolver mais o quadro, pois está fora de moda a descrição romântica e banidos os momentos de congraçamento entre os personagens, "agora somente se pintam as gangrenas com as cores roxas das chagas” (Castelo Branco, ib., 85). É uma contundente crítica ao realismo, escola que ganhava hegemonia. Mas há algo de paradoxal nesse reclamo, pois Maria Moisés é vazada numa linguagem em grande parte realista, tendo seus surtos românticos bastante suavizados. Estaria Camilo renegando o próprio trabalho?

Cremos que não. Ele chama a atenção para o exercício de superação que realizou nessa obra: ao beber na fonte da épica clássica, numa de suas principais vertentes, Camilo moveu de novo uma poderosa fórmula literária - o mito. Foi com esse poder da linguagem, que ciclicamente propõe a povos e culturas um reordenamento do cosmos, uma recriação da realidade, que nosso autor atingiu um 
sublime objetivo: a criação de uma narrativa mito-poética que fundava seu tempo.

Sensivel às profundas mudanças que o desenvolvimento do capitalismo e as revoluções burguesas trouxeram para seu mundo, Camilo, poeta e crítico de sua época, canta essas transformações, propondo miticamente novas formas de sociabilidade, nas quais as classes sejam superadas, as convenções morais desprezadas e novas relações estabelecidas entre os homens.

Enquanto o realismo expõe chagas e misérias, o autor romântico deseja escrever as formas de superação desse estado e, para isso, ele vai ao mito e à tradição épica para explicar seu mundo e instaurar novas fórmulas de vida. Mas também precisa ir além de seu tempo, buscando discursos ainda não misturáveis, antecipando etapas literárias para não ficar na análise cética dos realistas.

Para quem se der ao trabalho e ao prazer de retornar ao texto de Camilo, ficará claro que aqui apenas tocamos de leve nos paralelos entre a novela e seus modelos épicos. Outros personagens poderiam ainda ser melhor explorados, como o caso do pescador Bragadas, uma mistura entre a criada da princesa egípcia que adota Moisés (foi ele quem recolheu Maria e entregou aos patrões), o porqueiro Eumeu, o primeiro da casa de Odisseu a ter contato com o nobre patrão, ainda disfarçado (Bragadas é recompensado pelo pai de Maria por sua fidelidade). Enfim, nosso propósito ao conectar Maria Moisés com a épica antiga, grega e hebraica, é chamar a atenção para possiveis leituras que a obra de Camilo ainda reserva aos estudiosos da literatura portuguesa. 


\section{Bibliografia}

CAStelo Branco, C. Maria Moisés e outras novelas. Lisboa, Editorial Verbo, $3^{a}$ ed., s/d.

Franchetti, P. "Apresentação" de CASTElo BRANCO, C. Coração, cabeça e estômago. S. Paulo: Martins Fontes, 2003.

Homero. Odisséia. Trad. Carlos Alberto Nunes. R. Janeiro, Tecnoprint, s/d.

SARAIVA, A. J. E LoPes, O. História da Literatura Portuguesa. Porto, Porto Editora, $5^{\text {a }}$ ed., s/d.

SEIXO, M. A. O rio com regresso: ensaios camilianos. Lisboa: Presença, 2004. 